\title{
Prevalence of Wasting and its Associated Factors among Children age from 6-59 Months in Debre Tabor Town Amhara Region of Ethiopia 2019: A Multi-center Community-based Cross-sectional Study
}

\section{Bisrat Dessie Getu}

Debre Tabor Health Science College

Nigusie Selomon Tibebu ( $\nabla$ nigie1221@gmail.com )

Debre Tabor University https://orcid.org/0000-0002-5511-5812

Kefyalew Amogne Azanaw

Debre Tabor Health Science College

Libsuye Yalgaw Zimamu

Debre Tabor Health Science College

Gashaw Mekete Adal

Debre Tabor Health Science College

Tigabu Dessie Emiru

Debre Tabor University

Kendalem Asmare Atalell

University of Gondar

Research

Keywords: Wasting, Children, Debre Tabor, Ethiopia

Posted Date: September 17th, 2021

DOI: https://doi.org/10.21203/rs.3.rs-801162/v1

License: (c) (i) This work is licensed under a Creative Commons Attribution 4.0 International License.

Read Full License 


\section{Abstract}

Introduction: Wasting is acute malnutrition that has harmful short-term consequences for children and it is determined by inadequate diet. Therefore, this study was aimed to assess the prevalence and associated factors of wasting among children age 6-59 months at Debre Tabor town Ethiopia, 2019.

Method: A community-based cross-sectional study was conducted on wasting using simple and systematic random sampling. A sample of 436participants completed a questionnaire designed for the study. The questionnaire was coded and entered into Epi info version 7.2.0.1 and exported to SPSS 20.0 for data analysis. Principal component analysis (PCA) was used to compute family wealth status. Bivariable and multivariable logistic regression analyses were done to see which independent variables have an association with the dependent variable, and a $P$ value of less than 0.05 was considered as significant at $95 \% \mathrm{Cl}$.

Results: The result revealed that wasting for children age 6-59 months was $6.2 \%$ ( 95\% $\mathrm{Cl} 3.9 \%-8.5 \%$,). Children with the age group of 6-11 months were 4.3 times more likely to have wasted than those age group of 24-59 months [AOR: $4.3 ; 95 \% \mathrm{Cl}$ : 1.5-12.5]. Similarly, parents who have poor wealth status in their family are 3.1 times more likely to have wasted children than those who have rich wealth status in their family [AOR: 3.1 (1.01-9.35)]. Mothers who gave first birth at the age group of 20-25 years of age were 4.3 times more likely to have wasted children than those who gave birth at an age group of greater than 30 years [AOR: $(4.3(1.56-12.5)$ ].

Conclusion: Undernutrition especially wasting is still an important public health problem in children with an age group of 6-59 months. Age of the child, wealth status of the family, and giving the first birth before 20 years of age were significantly associated with wasting. Therefore, family wealth status should be modified, create awareness to the mothers regarding maternal and child health care and responsible bodies should be designed for further nutritional intervention programs.

\section{Introduction}

Wasting is acute malnutrition that has harmful short-term consequences for children and it is determined by inadequate diet. Furthermore, it is a direct cause of mortality among children 6-59 months of age(1). Wasting is a state of nutritional deficiency that brings severe health consequences, the most immediate being a pointed risk of mortality(2).

Globally wasting accounts for more than 51 million children(3). Each year more than 800,000 deaths are attributed to wasting. Moreover, approximately $13 \%$ of worldwide deaths among children under 5 years of age were attributed to wasting in 2015 , representing 875,000 preventable child deaths(2). There has been less progress regarding reducing the number of wasted children worldwide (4). Africa and Asia stand the greatest point of wasting(4).In Ghana 9.9\%(5), East Africa 6\%(6), in Uganda 12\%(7), Study done in Ethiopia 17\%(8), in Somalia regional state of Ethiopia 20\%(9) in south Ethiopia 14.6\%(10), East Bedawacho District South Ethiopia 7.6\%(10) in Sodozuriasouth Ethiopia 11.1\%(6), Damot gale south 
Ethiopia 9\%(11), in Afar regional state of Northeast Ethiopia 16.2\%(12) in Northern Ethiopia 24.6\%(13) in Lalibela Amhara region 8.9\%(14), In Gondar city Northwest Ethiopia 7.3\% (15), in Western Amhara 11.6\% (16) in East Belesa District Northwest Ethiopia 16\%(17).

According to the Ethiopia Demographic and Health Survey (EDHS) of 2019, the prevalence of wasting was $7 \%(18)$. The prevalence of wasting has decreased considerably, from $12 \%$ in 2005 to $7 \%$ in 2019 but in Ethiopia, the burden of child wasting has continued as a severe public health problem for decades(18).

About one-third of deaths among children below 5 years of age were attributed to Under-nutrition and it can lead children to be at greater risk of death and severe illness due to common childhood infections and consequently leads children to low school performance, physical and mental impairment $(13,19)$.

According to the revision of the literature, the following contributing factors of wasting in children were intra-uterine growth retardation, low birth weight, inadequate exclusive breastfeeding, inappropriate complementary feeding, low maternal education, low nutritional knowledge, insufficient energy and less micro-nutrient intake, birth spacing, socio-economic background, less food availability, poor sanitation, poor health services, low vaccination coverage, and infectious diseases $(3,20-23)$. As a result, this study was aimed to assess the burden of wasting among children aged 6-59 months at Debre Tabor Town, North West Ethiopia.

\section{Methods And Materials}

\section{Study design}

A cross-sectional study was conducted in Debre Tabor Town Northwest, Ethiopia, from March 1 to 30, 2019. The source population was all children aged 6-59 months in Debre Tabor Town during the specified study period. The study population was all selected children aged 6-59 months in Debre Tabor town during the specified study period. All children aged 6-59 months and their mothers with complete information. Averbal consent was taken from mothers/guardians. Socio-demographic, maternal, and child characteristics were used as independent variables.

\section{Sample size and sample size determination}

The sample size for the study was determined using the assumptions of single population proportion formula assuming the prevalence of wasting of $16 \%$ (17), $5 \%$ margin of error, $95 \%$ confidence level, adding $10 \%$ for possible non-response rate, design effect of 2 , the calculated sample size was 454 .

Out of 6 kebeles, 4 kebeles were selected randomly. The total sample size was allocated to each kebele proportionally. Households were selected using systematic random sampling and when there is more 
than one child 6-59 months of age in the selected household, a lottery method was used to randomly select the child.

\section{Data Collection Tools and Data Quality Control}

A structured questionnaire was used and mothers/guardians were interviewed face to face. Four bachelor's degree graduates with prior experience in data collection and fluent speakers of the local language were recruited.

The training was given to data collectors and supervisors about the questionnaire, selecting study participants, anthropometric measurements, and ethics. They were also standardized on taking anthropometric measurements. The questionnaire was pretested on $5 \%$ of the actual sample size other than the study area. The length of a child (aged 6-23 months) was measured with a horizontal wooden length board in a recumbent position. The height of a child (aged 24-59 months) was measured with a vertical wooden height board while the child standing upright on the board. The length and height measurements were read to the nearest $0.1 \mathrm{~cm}$. Weight was measured using a Seca digital weight scale and read to the nearest $0.1 \mathrm{~kg}$. All measurements were taken twice and the mean was used for analysis. Supervisors checked the completeness and consistency of the questionnaire.

\section{Dependent Variable}

- Wasting (below-2SD) children age from 6-59 months

\section{Independent Variables}

- Socio-economic and demographic variables (age, educational level, marital status, family wealth, and family size)

- MaternalCharacteristics (ANC start month, family planning use, age at first birth)

- Childs' Characteristics (age, sex of the child)

\section{Operational definitions}

Wasting is the weight-for-height z-score (WHZ) is below - 2 SD of the WHO median standard curve(4).

\section{Data analysis}

Data was checked, sorted, categorized, and coded. After coding data, it was fed to the computer to make them ready for processing and analysis. Data was entered into the EPI info version (7.2.0.1) and analyzed 
by using the SPSS 20.0 statistical program. Anthro software was used to convert nutritional data into Zscores of the indices; weight-for-height taking age, sex, weight, and height into consideration using WHO standards. Tables and charts were used to present results.

Binary logistic regression was used to identify variables associated with wasting, and variables significant at $P<0.25$ were entered into the final multivariable logistic regression model to identify significant factors at $P \leq 0.05$.

\section{Ethical consideration}

Ethical clearance was obtained from the school of the nursing ethical review committee on behalf of the University of Gondar. An official letter was written by a school of nursing to the DebreTabor town administrative health department office. Informed verbal consent was obtained from mothers/guardians before data collection. Privacy and confidentiality of respondents were secured.

\section{Result}

\section{Socio-Demographic Factors of the Study Participants}

From a total of 454 proposed study participants, 436 with a $96 \%$ response rate were included in the analysis. Among the total participants, $388(89 \%)$ were married in their marital status and the majority $297(68.1 \%)$ were fathers who have secondary and above education level. The majority of the $176(40.4 \%)$ were rich in family wealth status(Table 1 ).

Table-1

Characteristics of Participants for Wasting Among Children Age from 6 to 59 Months in Debre Tabor Town Amhara Region of Ethiopia, 2019 


\begin{tabular}{|c|c|c|c|c|}
\hline \multirow[t]{2}{*}{ Characteristics } & \multirow[t]{2}{*}{ Categories } & \multirow[t]{2}{*}{$\begin{array}{l}\text { Total } \\
\mathrm{N}=436\end{array}$} & \multicolumn{2}{|c|}{ child Status of a } \\
\hline & & & Wasted & $\begin{array}{l}\text { Not } \\
\text { wasted }\end{array}$ \\
\hline Mothers' age group & $20-24$ & $31(7.1 \%)$ & 6 & 25 \\
\hline \multirow[t]{2}{*}{ Mean $=31 \pm 5.41$ SD } & $25-29$ & $181(41.5 \%)$ & 11 & 170 \\
\hline & $\geq 30$ & $224(51.4 \%)$ & 10 & 214 \\
\hline \multirow{3}{*}{$\begin{array}{l}\text { Mother age group at first } \\
\text { birth }\end{array}$} & $20-25$ & $97(22.2 \%)$ & 12 & 85 \\
\hline & $26-29$ & $238(54.6 \%)$ & 8 & 230 \\
\hline & $\geq 30$ & $101(23.2 \%)$ & 7 & 94 \\
\hline \multirow[t]{3}{*}{ Mothers' educational level } & No formal education & $99(22.7 \%)$ & 8 & 91 \\
\hline & Primary education & $105(24.1 \%)$ & 7 & 98 \\
\hline & $\begin{array}{l}\text { Secondary education and } \\
\text { above }\end{array}$ & $23253.2 \%)$ & 12 & 220 \\
\hline \multirow[t]{3}{*}{ Fathers' educational level } & No formal education & $56(12.8 \%)$ & 5 & 51 \\
\hline & Primary education & 83(19\%) & 9 & 74 \\
\hline & $\begin{array}{l}\text { Secondary education and } \\
\text { above }\end{array}$ & $297(68.1 \%)$ & 13 & 284 \\
\hline \multirow[t]{2}{*}{ Marital status of a mother } & Married & $388(89 \%)$ & 20 & 368 \\
\hline & Single & $48(11 \%)$ & 7 & 48 \\
\hline \multirow[t]{2}{*}{ Family planning use } & Yes & $323(74.1 \%)$ & 19 & 304 \\
\hline & No & $113(25.9)$ & 8 & 105 \\
\hline \multirow[t]{2}{*}{ ANC start month } & $\leq 3$ months & $291(66.7 \%)$ & 18 & 273 \\
\hline & $>3$ months & $145(33.3 \%)$ & 9 & 136 \\
\hline \multirow[t]{2}{*}{ Family size } & Less than five & $350(80.3 \%)$ & 20 & 330 \\
\hline & Greater than equal to five & 86(19.7\%) & 7 & 79 \\
\hline \multirow[t]{2}{*}{ Sex of child } & Male & $233(53.4 \%)$ & 11 & 222 \\
\hline & Female & $203(46.6 \%)$ & 16 & 187 \\
\hline \multirow[t]{3}{*}{ Child age } & 6-11 months & $131(30 \%)$ & 13 & 118 \\
\hline & $12-23$ months & $105(24.1 \%)$ & 8 & 97 \\
\hline & 24-59 months & $200(45.9 \%)$ & 6 & 194 \\
\hline
\end{tabular}


Family wealth status

\begin{tabular}{l} 
Poor \\
Medium \\
\hline Rich
\end{tabular}

142(32.6\%)

14

128

$118(27.1 \%) \quad 8$

110

Rich

$176(40.4 \%)$

5

171

SD: Standard Deviation.

\section{Wasting Among Children Age from 6 to 59 Months in Debre Tabor Town Amhara Region of Ethiopia}

From the total participants of the survey age from 6 to 59 months of children, $6.2 \%(95 \% \mathrm{Cl} 3.9 \%-8.5 \%)$ were found wasted (Figure 1)

\section{Factors Associated with wasting among Children Age from 6 to 59 Months in Debre Tabor Town Amhara Region of Ethiopia}

Bivariable and multivariable logistic regression analyses were used to determine factors affecting the wasting of children age from 6 to 59 months. The bivariable analysis showed that birth order, sex of the child, age of the mother at first birth, marital status of the participant, mothers' educational level, fathers' educational level, place of delivery,

Bivariable and multivariable logistic regression analyses were used to determine factors affecting the wasted of children age from 6 to 59 months. The bivariable analysis showed that the educational status of the father, educational status of the mother, age of the child, wealth status of the family, age of the mother, and age of the mother at first birth was associated with wasting considering $p$-value $\leq 0.2$. For adjusting potential confounders those variables which were significant at bivariable analysis were entered into multivariable logistic regression. The result revealed that the age of the child, wealth status of the family, and age of the mother at first birth were significantly associated with wasting for children age 6-59 months. However, the remaining listed above variables were not significant at a $p$-value $\leq$ of 0.05 (Table-2)

Table 2

Bivariate and Multivariable Logistic Regression Analyses for Wasting Among Children Age from 6 to 59 Months in Debre Tabor Town Amhara Region of Ethiopia, 2019 


\begin{tabular}{|c|c|c|c|c|c|}
\hline \multirow[t]{2}{*}{ Variables } & \multirow[t]{2}{*}{ Categories } & \multirow{2}{*}{$\begin{array}{l}\text { Total } \\
\mathrm{N}=436\end{array}$} & \multicolumn{2}{|c|}{ Status of children } & \multirow[t]{2}{*}{$\mathrm{AOR} / 95 \% \mathrm{Cl}$} \\
\hline & & & Wasted & $\begin{array}{l}\text { Not } \\
\text { Wasted }\end{array}$ & \\
\hline \multirow[t]{3}{*}{ Mothers' education } & No formal education & $99(22.7 \%)$ & 8 & 91 & $\begin{array}{l}2.11(0.57- \\
7.81)\end{array}$ \\
\hline & Primary education & $105(24.1 \%)$ & 7 & 98 & $\begin{array}{l}2.24(0.78- \\
6.44)\end{array}$ \\
\hline & $\begin{array}{l}\text { Secondary education } \\
\text { and above }\end{array}$ & 232(53.2\%) & 12 & 220 & 1 \\
\hline \multirow[t]{3}{*}{ Fathers' education } & No formal education & $56(12.8 \%)$ & 5 & 51 & $\begin{array}{l}1.01(0.32- \\
3.15)\end{array}$ \\
\hline & Primary education & $83(19.1 \%)$ & 9 & 74 & $\begin{array}{l}0.93(0.33- \\
2.63)\end{array}$ \\
\hline & $\begin{array}{l}\text { Secondary education } \\
\text { and above }\end{array}$ & $297(68.1 \%)$ & 13 & 284 & 1 \\
\hline \multirow[t]{3}{*}{ Mothers'age group } & $20-24$ & $31(7.1 \%)$ & 6 & 25 & $\begin{array}{l}3.09(0.87- \\
10.95)\end{array}$ \\
\hline & $25-29$ & 181(41.5\%) & 11 & 170 & $\begin{array}{l}1.63(0.63- \\
4.19)\end{array}$ \\
\hline & $\geq 30$ & 224(51.4\%) & 10 & 214 & 1 \\
\hline \multirow[t]{3}{*}{$\begin{array}{l}\text { Mothers'age group at } \\
\text { first birth }\end{array}$} & $20-25$ & $97(22.2 \%)$ & 12 & 85 & $\begin{array}{l}4.35(1.56- \\
12.5)\end{array}$ \\
\hline & $26-29$ & $238(54.6 \%)$ & 8 & 230 & $\begin{array}{l}0.67(0.22- \\
2.00)\end{array}$ \\
\hline & $\geq 30$ & 101(23.2\%) & 7 & 94 & 1 \\
\hline \multirow[t]{3}{*}{ Child age } & 6-11 months & 131(30\%) & 13 & 118 & $\begin{array}{l}4.32(1.49- \\
12.55)\end{array}$ \\
\hline & $12-23$ months & 105(24.1\%) & 8 & 97 & $\begin{array}{l}2.58(0.82- \\
8.1)\end{array}$ \\
\hline & 24-59 months & $200(45.9 \%)$ & 6 & 194 & 1 \\
\hline \multirow[t]{3}{*}{ Family wealth } & Poor & 142(32.6\%) & 14 & 128 & $\begin{array}{l}3.07(1.01- \\
9.35)\end{array}$ \\
\hline & Medium & 118(27.1\%) & 8 & 110 & $\begin{array}{l}2.53(0.76- \\
8.38)\end{array}$ \\
\hline & Rich & $176(40.4)$ & 5 & 171 & 1 \\
\hline
\end{tabular}


Children with an age group of 6-11 months were 4.3 times more likely to have wasted than those children with an age group of 24-59 months [AOR: $4.3 ; 95 \% \mathrm{Cl}$ : 1.5-12.5]. Similarly, parents who have poor wealth status in their family 3.1 times more likely to have wasted children than those who have rich wealth status in their family [AOR: $3.1(1.01-9.35)$ ]. Children of mothers' who give first birth at the age group of 20-25 years of age were 4.3 times more likely to have wasted than those who give birth at the age group of greater than 30 years.

\section{Discussion}

Under-nutrition among children age 6-59 months of age is still a major public health problem in developing countries, including Ethiopia. The magnitude of wasting in this study was $6.2 \%(95 \% \mathrm{Cl}$ $3.9 \%-8.5 \%)$.

Age of the child, wealth status of the family, and giving the first birth before 20 years of age was associated with higher odds of wasting.

This study was in line with the study done at Gondar city Northwest Ethiopia 7.3\%(15), East Bedawacho District South Ethiopia 7.6\%(10), WolaytaSodo Town, Southern Ethiopia 7.8\%(24)

EDHS 2019 7\%(18) and in East Africa 6\% (6). However, this study was lower as evaluated to the study done in East Belesa District Northwest Ethiopia16\%(17), in Western Amhara Region Ethiopia 11.6\%(16), Norther Ethiopia 24.6\%(13), Afar regional state Northeast Ethiopia 16.2\%(12), Damot gale South Ethiopia 9\%(11), Sodozuria South Ethiopia 11.1\%(6), in South Ethiopia 14.6\%(10), Somalia regional state of Ethiopia 20\%(9), a study done in Ethiopia 20\%(8), Uganda 12\%(7), in Ghana 9.9\%(5). The possible reason might be due to different study periods and most studies were nationwide while this study was specific to Debretabor town Ethiopia.

In the present study children's age was one of the predictors of wasting among children age 6-59 months. Children who had 6-11 months of age were 4.3 times more likely to have wasted than 24-59 months of age. The result is supported by the research done in North ShewaOromia, Ethiopia(20), Lalibela, Northern Ethiopia(14), Uganda(25), Myanmar South Asia(26). The possible justification might be with increase the child age the frequency of wasting decrease due to the increased susceptibility of younger children to infection/illness(22).

Another predictor of wasting for children age 6-59 months was family wealth status. In this study families who have poor wealth status 3.1 times more likely to have wasted children than those families who have rich wealth status. This study is supported by the study done in Uganda(7), Gondar town northwest Ethiopia(15), Dabat, northwest Ethiopia(8). The possible reason might be due to children who have poor family wealth status lack adequate nutrition's in their household, and this leads to a nutritional imbalance between demand and supply. 
The last predictor of wasting for this study was maternal age at first birth. Children of mothers who give first birth at the age group of 20-24 years of age were 4.3 times more likely to have wasted children than those who gave birth at the age group of greater than 30 years. The possible reasons might be due to the high demand for nutrition at first conception, again this leads to the child being wasted. Furthermore, the income of Youngers has a great impact on their family nutritional status since most of the Youngerswithin the age group of 20-24 are unemployed.

\section{Limitations of the Study}

The present study has some limitations. It was focused on children's characteristics rather than environmental factors, and also the study is cross-sectional it does not show a cause-effect relationship between wasting and associated factors.

\section{Conclusion}

Undernutrition especially wasting is still an important public health problem in children with an age group of 6-59 months. Age of the child, wealth status of the family, and giving the first birth before 20 years of age were significantly associated with wasting. Therefore, family wealth status should be modified, create awareness to mothers regarding maternal and child health care and responsible bodies should be designed for further nutritional intervention programs.

\section{Abbreviations}

ANC=Ante Natal Care, $\mathrm{AOR}=$ Adjusted Odds Ratio, $\mathrm{Cl}=$ Confidence Interval, $\mathrm{COR}=$ Crude Odds Ratio, $\mathrm{HH}=$ House Holds, KM = Kilo Meter, PCA = Principal Component Analysis, SPSS = Statistical Package for Social Sciences, $\mathrm{WHO}=$ World Health Organization

\section{Declarations}

\section{Ethical Approval and Consent to Participate:}

Ethical clearance was obtained from the school of the nursing ethical review committee on behalf of the University of Gondar review board. The verbal informed consent was acceptable and approved by the ethical review board on the behalf of the University of Gondar.

A permission letter was obtained from the Debre Tabor town department of health. Participants were informed about voluntarism and that they can withdraw at any time of the study if they want not to respond. For those who were a volunteer to participate, verbal informed consent was obtained from the parent/legal guardian/ for the children involved in this study. At the end of the interview, participants were informed about wasting and associated potential effects. 


\section{Consent to publication:}

Not applicable

\section{Availability of the Data:}

Data will be available upon request from the corresponding author.

\section{Acknowledgment}

The authors would like to thank Amhara Regional Health Bureau for its financial support. Besides, we want to acknowledge data collectors and supervisors for their commitment to collect the data accurately.

\section{Authors' Contribution:}

All authors made substantial contributions to conception, design, acquisition of data, or analysis and interpretation of data. And took part in drafting the article or revising it critically for important intellectual content; agreed to submit to the current journal; gave final approval of the version to be published, and agree to be accountable for all aspects of the work. All authors have read and approved the final manuscript.

\section{Disclosure}

The authors report no conflicts of interest

\section{Funding:}

This research didn't receive any grant from any funding agency in the public, commercial, or not-for-profit sectors.

\section{References}

1. Paré BC, Dahourou DL, Ahmed Kabore AS, Kinda R, Ouaro B, Dahany M-M, et al. Prevalence of wasting and associated factors among 6 to 23 months old children in the Sahel Region of Burkina Faso. The Pan African Medical Journal. 2019;34.

2. Harding KL, Aguayo VM, Webb P. Factors associated with wasting among children under five years old in South Asia: Implications for action. PloS one. 2018;13(7):e0198749. 
3. Khan GN, Turab A, Khan MI, Rizvi A, Shaheen F, Ullah A, et al. Prevalence and associated factors of malnutrition among children under-five years in Sindh, Pakistan: a cross-sectional study. BMC nutrition. 2016;2(1):69.

4. Khara T, Mwangome M, Ngari M, Dolan C. Children concurrently wasted and stunted: A meta-analysis of prevalence data of children 6-59 months from 84 countries. Matern Child Nutr. 2018;14(2):e12516.

5. Ali Z, Saaka M, Adams A-G, Kamwininaang SK, Abizari A-R. The effect of maternal and child factors on stunting, wasting and underweight among preschool children in Northern Ghana. BMC nutrition. 2017;3(1):31.

6. Tufa EG, Dake SK, Bekru ET, Tekle HA, Bobe TM, Angore BN, et al. Magnitude of wasting and underweight among children 6-59 months of age in Sodo Zuria District, South Ethiopia: a community based cross-sectional study. BMC Res Notes. 2018;11(1):790.

7. Odei Obeng-Amoako GA, Karamagi CAS, Nangendo J, Okiring J, Kiirya Y, Aryeetey R, et al. Prevalence and determinants of stunting and wasting among public primary school children in Gondar town, northwest, Ethiopia Maternal \& Child Nutrition. 2020:e13074.

8. Derso T, Tariku A, Biks GA, Wassie MM. Stunting, wasting and associated factors among children aged 6-24 months in Dabat health and demographic surveillance system site: A community based cross-sectional study in Ethiopia. Bmc pediatrics. 2017;17(1):96.

9. Ma'alin A, Birhanu D, Melaku S, Tolossa D, Mohammed Y, Gebremicheal K. Magnitude and factors associated with malnutrition in children 6-59 months of age in Shinille Woreda, Ethiopian Somali regional state: a cross-sectional study. BMC Nutrition. 2016;2(1):1-12.

10. Betebo B, Ejajo T, Alemseged F, Massa D. Household food insecurity and its association with nutritional status of children 6-59 months of age in east Badawacho District, south Ethiopia. Journal of environmental and public health. 2017;2017.

11. Abera L, Dejene T, Laelago T. Prevalence of malnutrition and associated factors in children aged 659 months among rural dwellers of damot gale district, south Ethiopia: community based cross sectional study. Int J Equity Health. 2017;16(1):111.

12. Gebre A, Reddy PS, Mulugeta A, Sedik Y, Kahssay M. Prevalence of malnutrition and associated factors among under-five children in pastoral communities of afar regional state, Northeast Ethiopia: a community-based cross-sectional study. Journal of nutrition and metabolism. 2019;2019.

13. Kelati H, Mengiste B, Alemayehu T, Damtew B. Prevalence of acute malnutrition and its associated factors among children aged 6-59 months in Mai-Aini Eritrean Refugees' Camp, Northern Ethiopia. J Nutr Food Sci. 2014;5(1):336.

14. Yalew B, Amsalu F, Bikes D. Prevalence and factors associated with stunting, underweight and wasting: A community based cross sectional study among children age 6-59 months at Lalibela Town, Northern Ethiopia. J Nutr Disorders Ther. 2014;4(147):2161-0509.1000147.

15. Gelu A, Edris M, Derso T, Abebe Z. Undernutrition and associated factors among children aged 6-59 months living in slum areas of Gondar city, northwest Ethiopia: a cross-sectional study. Pediatric 
health medicine therapeutics. 2018;9:81.

16. Demilew YM, Alem AT. Food security is not the only solution to prevent under-nutrition among 6-59 months old children in Western Amhara region, Ethiopia. BMC Pediatr. 2019;19(1):7.

17. Fentahun $W$, Wubshet $M$, Tariku A. Undernutrition and associated factors among children aged 6-59 months in East Belesa District, northwest Ethiopia: a community based cross-sectional study. BMC Public Health. 2016;16(1):506.

18. ICF EEMD. Health Survey. 2019. Key Indicators Rockville, Maryland, USA: EPHI and ICF. 2019.

19. Tufa EG, Dake SK, Bekru ET, Tekle HA, Bobe TM, Angore BN, et al. Magnitude of wasting and underweight among children 6-59 months of age in Sodo Zuria District, South Ethiopia: a community based cross-sectional study. BMC Res Notes. 2018;11(1):790.

20. Mengistu K, Alemu K, Destaw B. Prevalence of malnutrition and associated factors among children aged 6-59 months at Hidabu Abote District, North Shewa, Oromia Regional State. J nutr disorders ther. 2013;1:1-15.

21. Geberselassie SB, Abebe SM, Melsew YA, Mutuku SM, Wassie MM. Prevalence of stunting and its associated factors among children 6-59 months of age in Libo-Kemekem district, Northwest Ethiopia; A community based cross sectional study. PloS one. 2018;13(5):e0195361.

22. Ahmad S Prevalence and Associated Factors of Undernutrition Among 6-59 Months Children in Tehsil Battagram, Pakistan. Pakistan (3/30/2020). 2020.

23. Asfaw M, Wondaferash M, Taha M, Dube L. Prevalence of undernutrition and associated factors among children aged between six to fifty nine months in Bule Hora district, South Ethiopia. BMC Public health. 2015;15(1):41.

24. Eshete H, Abebe Y, Loha E, Gebru T, Tesheme T. Nutritional status and effect of maternal employment among children aged 6-59 months in Wolayta Sodo town, southern Ethiopia: a cross-sectional study. Ethiopian journal of health sciences. 2017;27(2):155-62.

25. Odei Obeng-Amoako GA, Wamani H, Conkle J, Aryeetey R, Nangendo J, Mupere E, et al. Concurrently wasted and stunted 6-59 months children admitted to the outpatient therapeutic feeding programme in Karamoja, Uganda: Prevalence, characteristics, treatment outcomes and response. PloS one. 2020;15(3):e0230480.

26. Blankenship JL, Cashin J, Nguyen TT, Ip H. Childhood stunting and wasting in Myanmar: Key drivers and implications for policies and programmes. Maternal Child Nutrition. 2020;16:e12710.

\section{Figures}




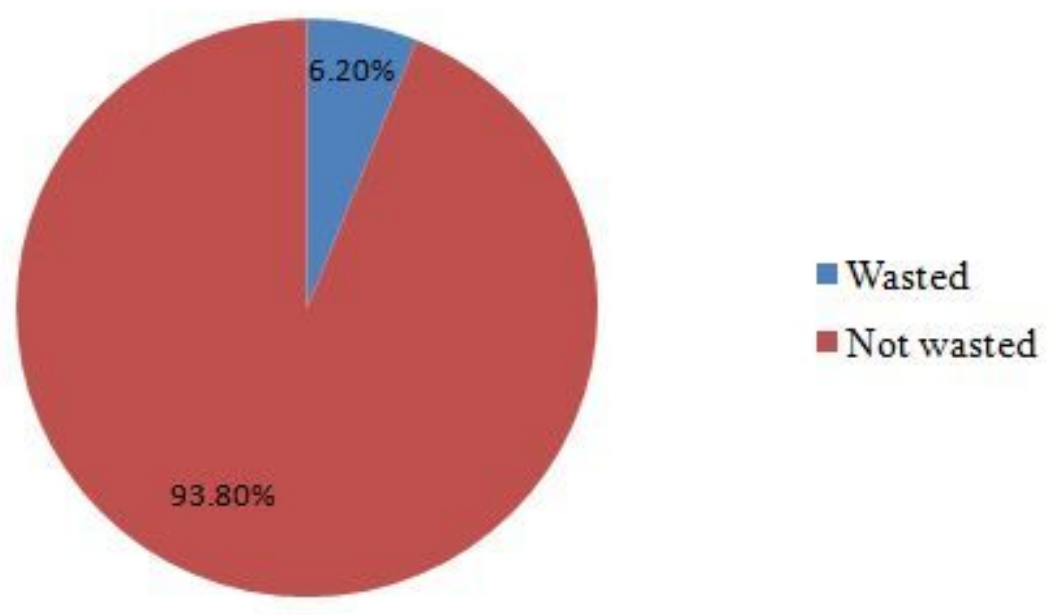

\section{Figure 1}

Prevalence of wasting among children age from 6-59 months in Debre Tabor town Amhara Region of Ethiopia, 2019. 